\title{
Food Adulteration and Contamination-A Catastrophe
}

\author{
*G.Vyralakshmi ${ }^{1}$, G.Jayasheela ${ }^{2}$ \\ ${ }^{1}$ B.A.LLB(Hons), Department of Law, Saveetha School of Law, Saveetha University, Chennai, India \\ ${ }^{2}$ Assistant Professor of Law, Department of Law, Saveetha School of Law, Saveetha University, Chennai,India \\ Corresponding Author: G.Vyralakshmi
}

\begin{abstract}
In Chennai, Tamil Nadu food were contaminated and adulterated which are consumed by the consumers a those-hold level, food service firms such as hotels,catering service, etc. and especially when the street food are consumed. Food colouring are done by using highly chemical mixed colours which are not permitted to use in food items which are not good for our health and it may lead to food-borne diseases. Contamination of mycotoxins, metals and pesticides in food items which we consume daily such as milk, rice,etc which were found with highly toxic and carcinogenic. More number of people die every year due to food borne diseases. In order to prevent such things, food safety measures are prominent with an aim to prevent the consumers from health hazards and empowering the regulatory system.It is desirable to prevent adulteration and contamination of food items, if the consumers are aware of health hazards.
\end{abstract}

Keywords: Food adulteration, Toxins, Chennai city, Food borne disease and

Date of Submission: 29-06-2017

Date of acceptance: $20-07-2017$

\section{Introduction}

Food borne disease are widespread globally. They results in various diseases which would end the people's life into risk. It leaves to health hazard and it was quiet challenging for all the nations who suffers due to food adulteration. Especially India was affected due to food adulteration and contamination. It all started or raised in the situation where our nation's economy was opened and LPG i.e Liberalisation,Privatisation and Globalisation. At national level, food trade enhanced easy accessibility, affordability for its customers through various offers and safety in good quality of foods materials. In recent times food exports were increased but there are few hurdles like food toxicity due to privatisation and liberalisation which changed the trade pattern of food production and consumption.

\section{Objective}

- To study about the food adulteration and food contamination in Chennai

- To analyses the existing legal framework on food adulteration.

\subsection{Food security and its challenges}

In our society, food safety is a growing issue with aggressive case of adulteration and contamination of essential foods items that can be a vital source for disease, infection or toxic poisoning. Food would be contaminated or spoiled mostly when the handling process from the primary producers to the consumers occurs i.e starting from food production to serving or cooking. Adulterants are the non-nutritious substances which are not good for the health are either intentionally,deliberately added or unintentionally added into the food items. Mycotoxins such as, aflatoxins, ochratoxins, fumonisins, zeralenone, patulin, and trichothecenes produced by moulds are found in food supply chain. At community level, serious outbreaks of food-borne diseases have been reported from time to time.

Food-borne diseases are a critical issues on health hazard and vital cause of morbidity and mortality in developing countries. Most of cases are unreported and scientific investigation for such issues cannot be made available. In present circumstances, the problems related to food borne diseases are slowly avoided and the enquirers and investigations for such issues are done just for eye-wash. The exact fact of the issues related to food-borne diseases in country like India are not aware of the consequences and it would take plenty of time to understand by the people. Even most of the studies shows the problems of food-borne diseases, still it lacks in its proof.This may be due to the people who cannot recognise the problem, and the food safety commission which lacks in its duty. The actual scene of food -borne diseases to be spreader to all people in order to prevent them from any health hazard and it was considered to make lots of research in that particular field but there also our government lacks in doing so. In recent years,food adulteration has developed from a less amount fraud to a huge profitability and luxurious business. Adulteration of milk has been a trending issue since the past several 
months. But the adulteration was started several years before itself. It was said that cotton seed oils are mixed in the milk which would give more number of quantity and colour which also freely gives the diseases which are highly sensitive. Through the wash of liberalisation many foodstuffs are emerged and modernisation also one of the reason for food adulteration. The Food safety must investigate whether the foods are good for health or it possess to health hazard which would be concentrated for Indian consumers. Several countries keenly noticed the issue of food adulteration and sorted out but still India is lacking behind.

\subsection{Food adulteration and its impact in Chennai.}

In Chennai, most of the consumers are addicted to street foods and stored foods which are easily contaminated and it leads to obesity, diabetes and upto the extent of cancer. In earlier stage, Indian families used to cook food at home and be healthy later on, due to the modernisation and urbanisation, people used to stuff the food items in the refrigerator and buy the stored foods which was kept in the ice box for more than a week. Also usage of plastics leads to cancer. As Chennai became a multicultural city, it cannot concentrate on all the food items which are not the native of India. Many foreign food items are sold in our market which the people would be difficult to adapt. The multi cuisine restaurants may use non-permitted colours and toxic items which are added for flavours and taste but good for the health. As now Indians are more affected on diabetes and it results in dieting the food items which would break the regular intake of food items.

Mostly the adulterated products are rooted from the raw materials. In addition, this study assesses consumer perceptions of and attitudes towards these contaminated food items and explores how adulterated foods and foodstuffs affect consumer health. The empirical data were collected from 30 consumers in Chennai.

\section{Figures And Tables}

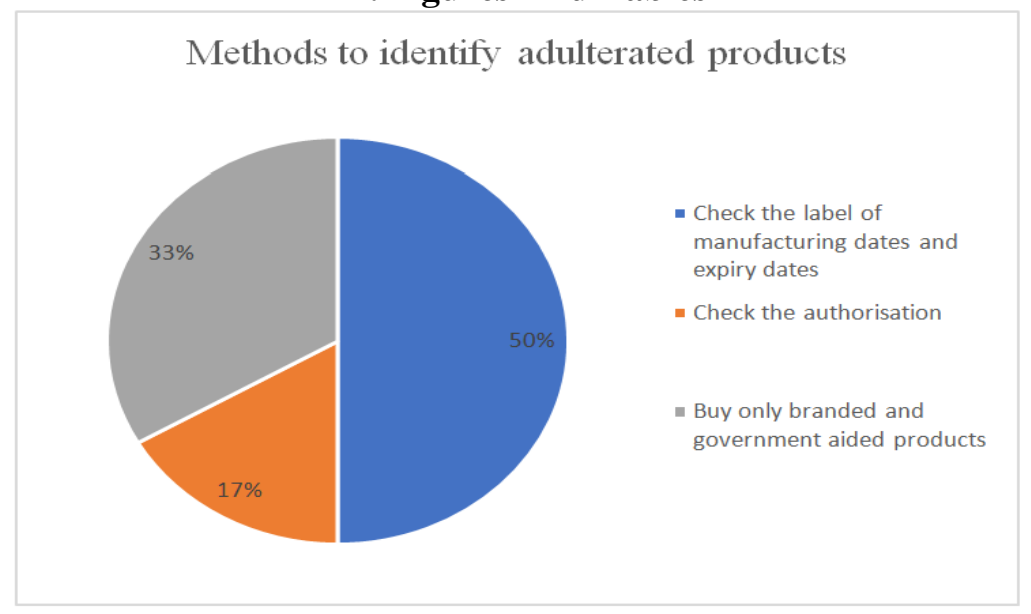

fig. 1

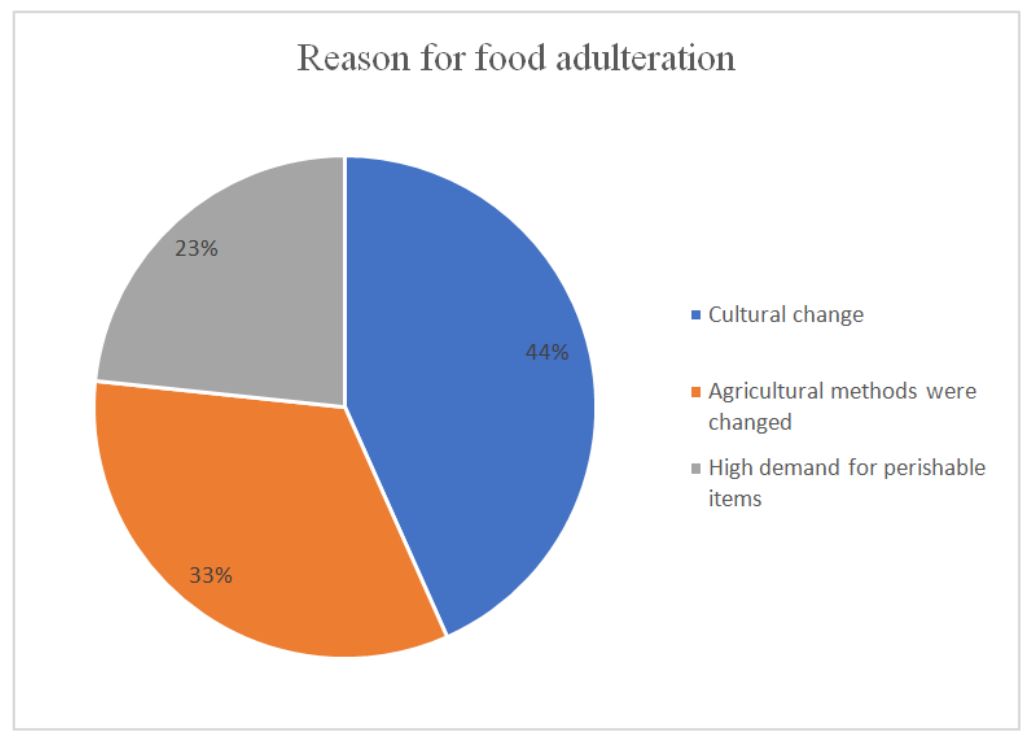

fig. 2 


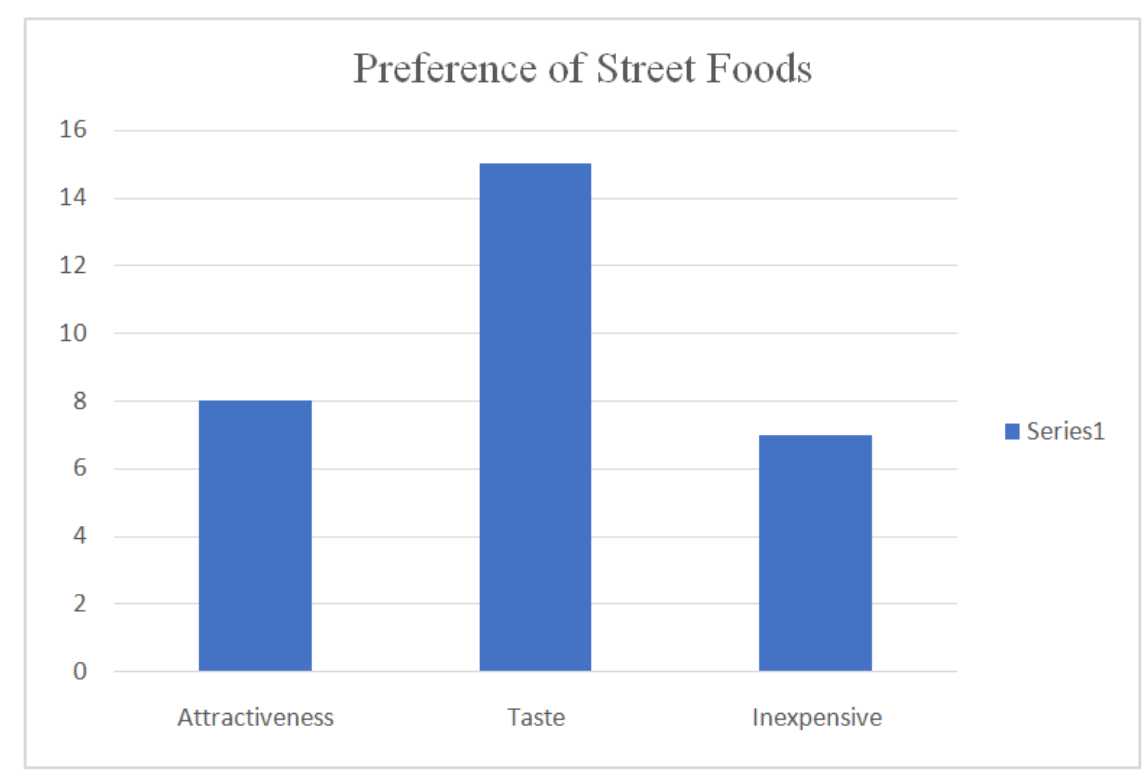

fig. 3

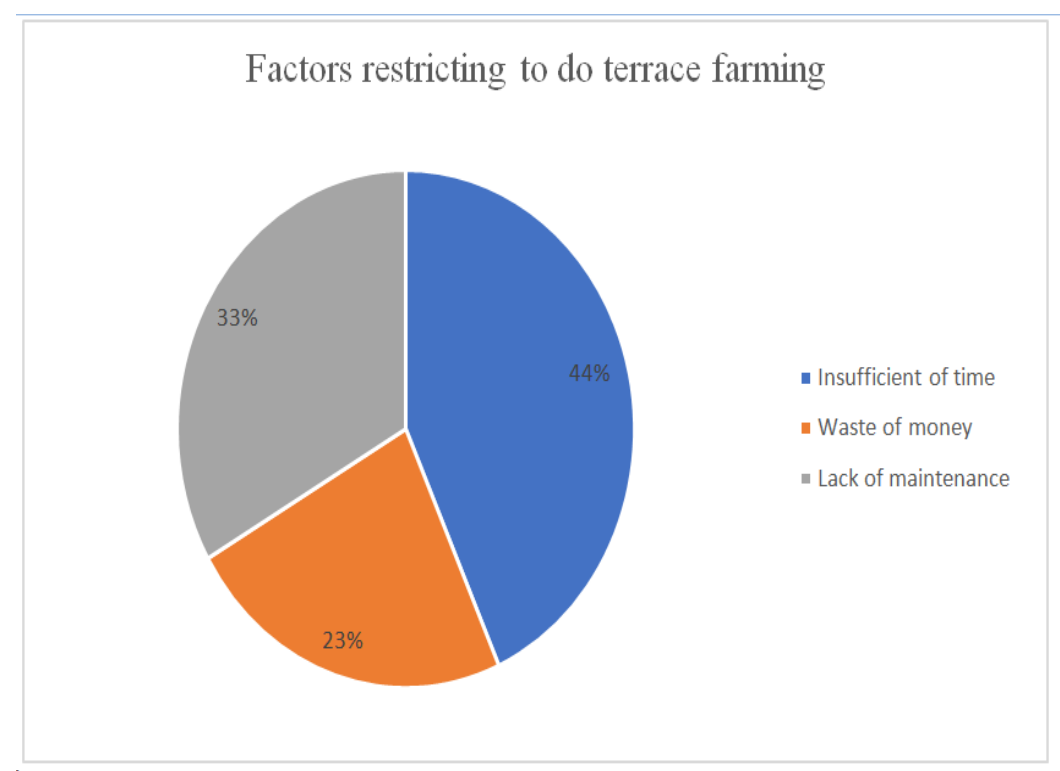

fig.4

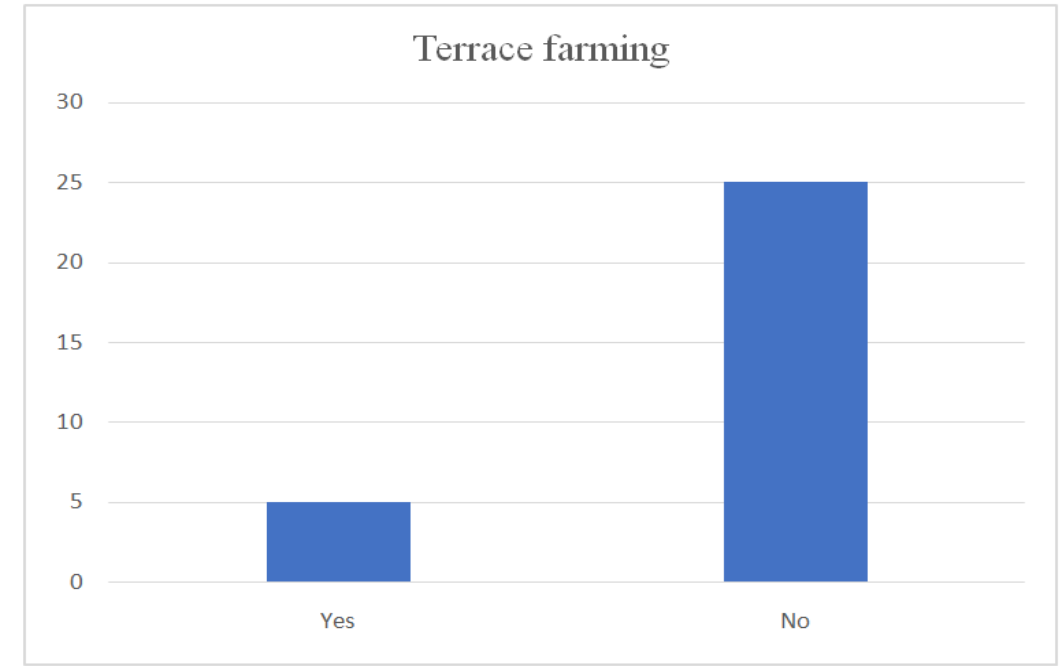

fig.5 


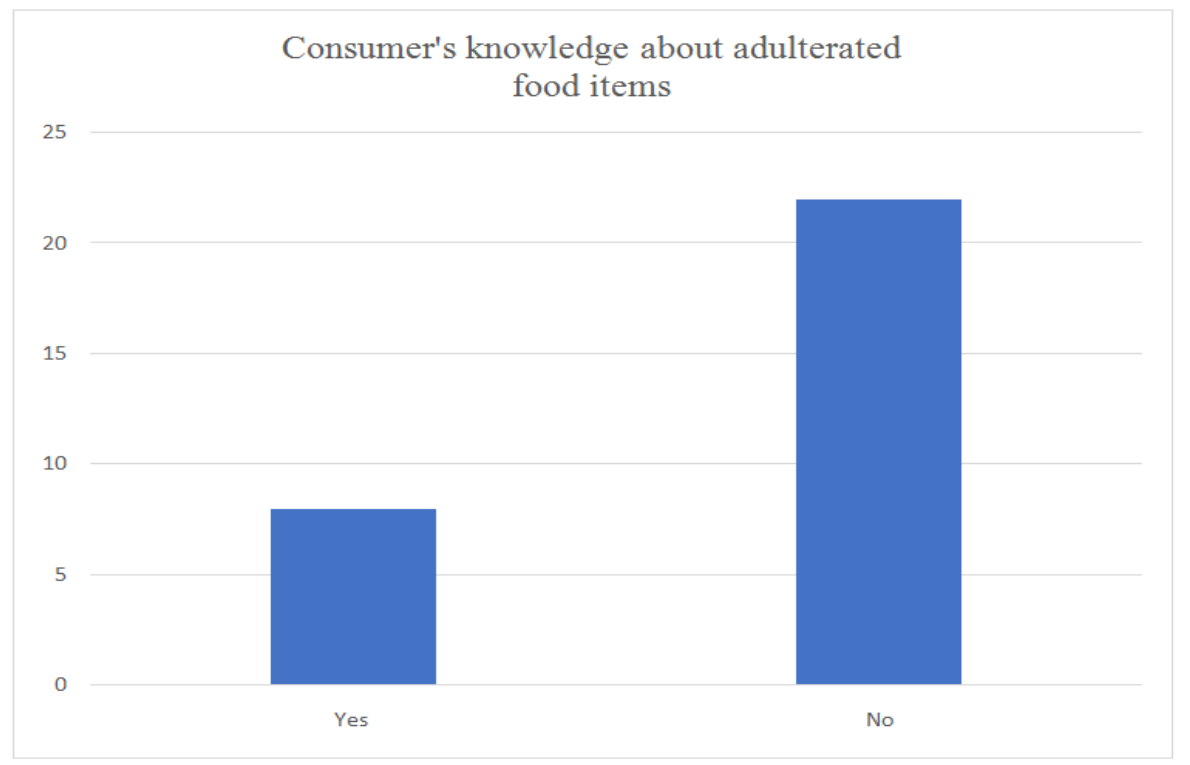

fig.6

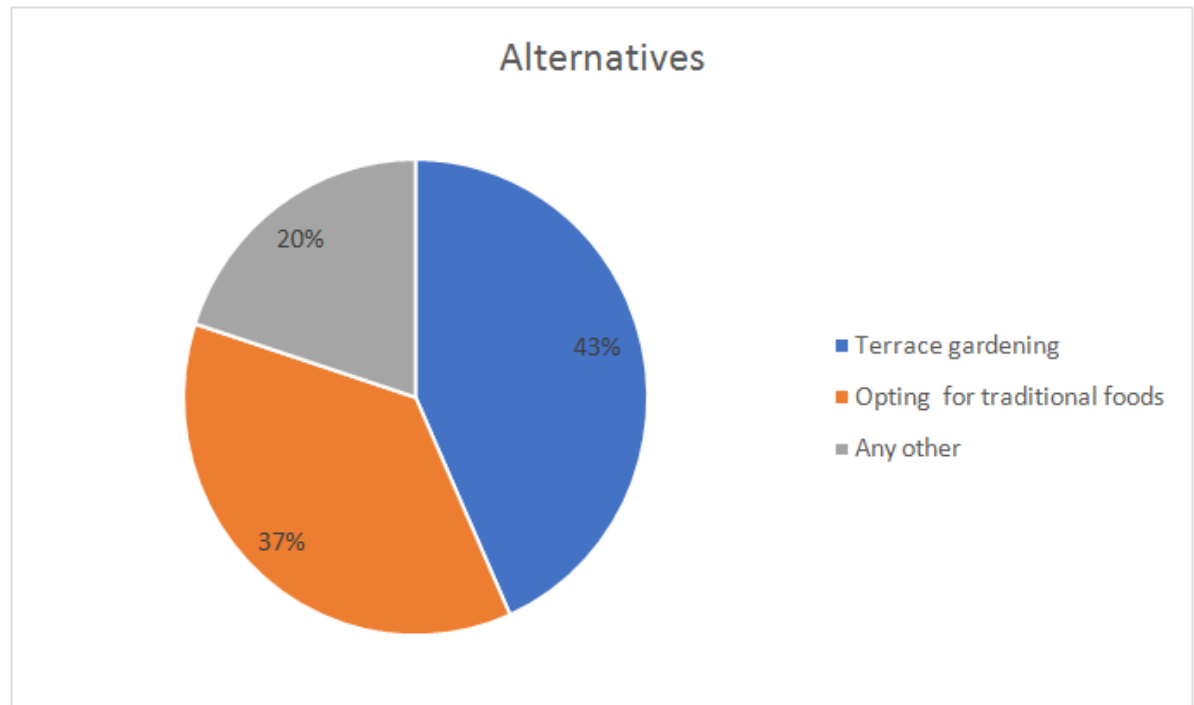

fig.7

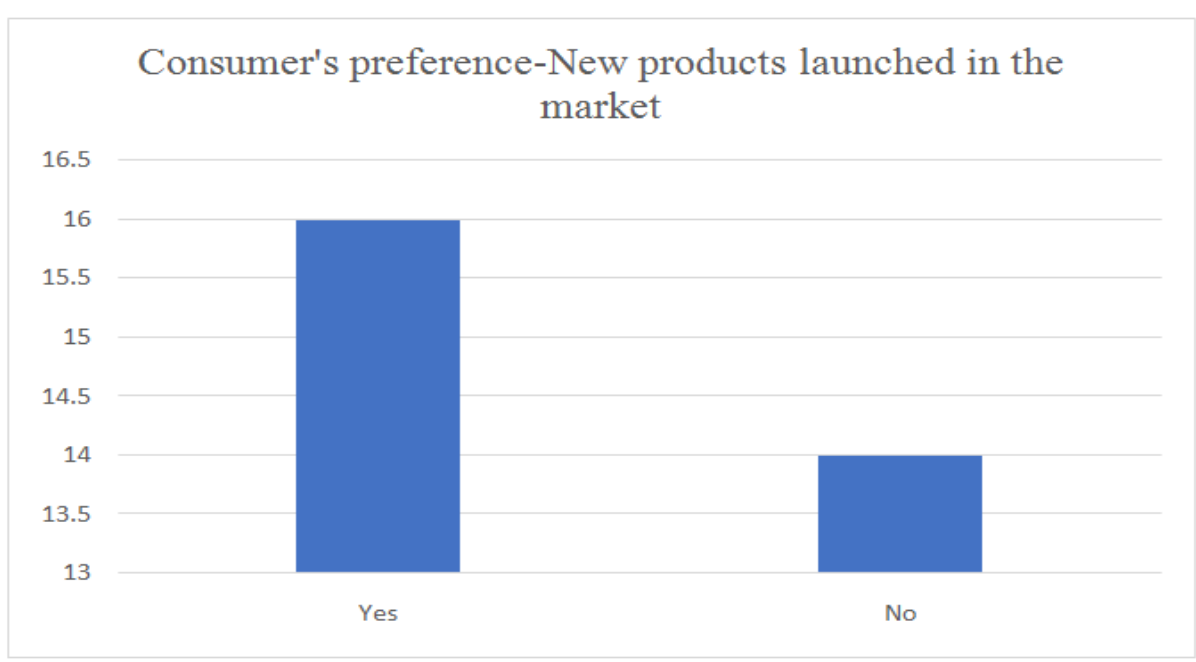

fig. 8 


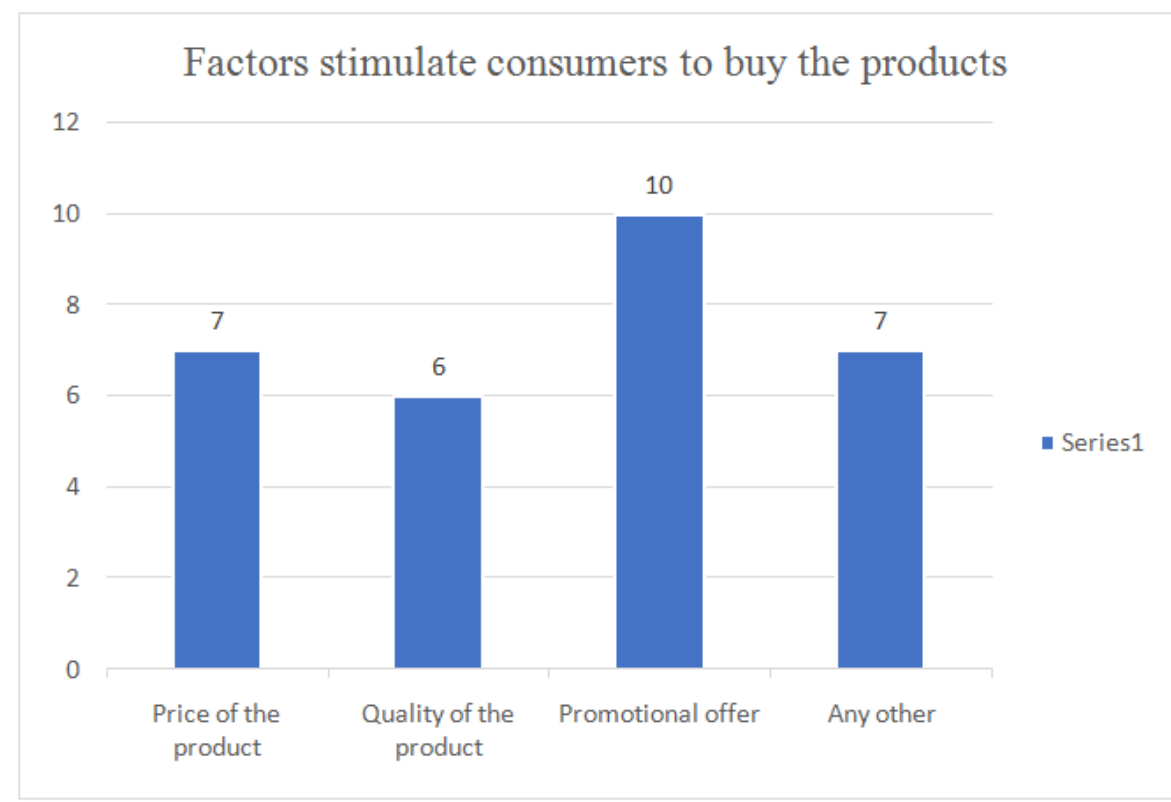

fig.9

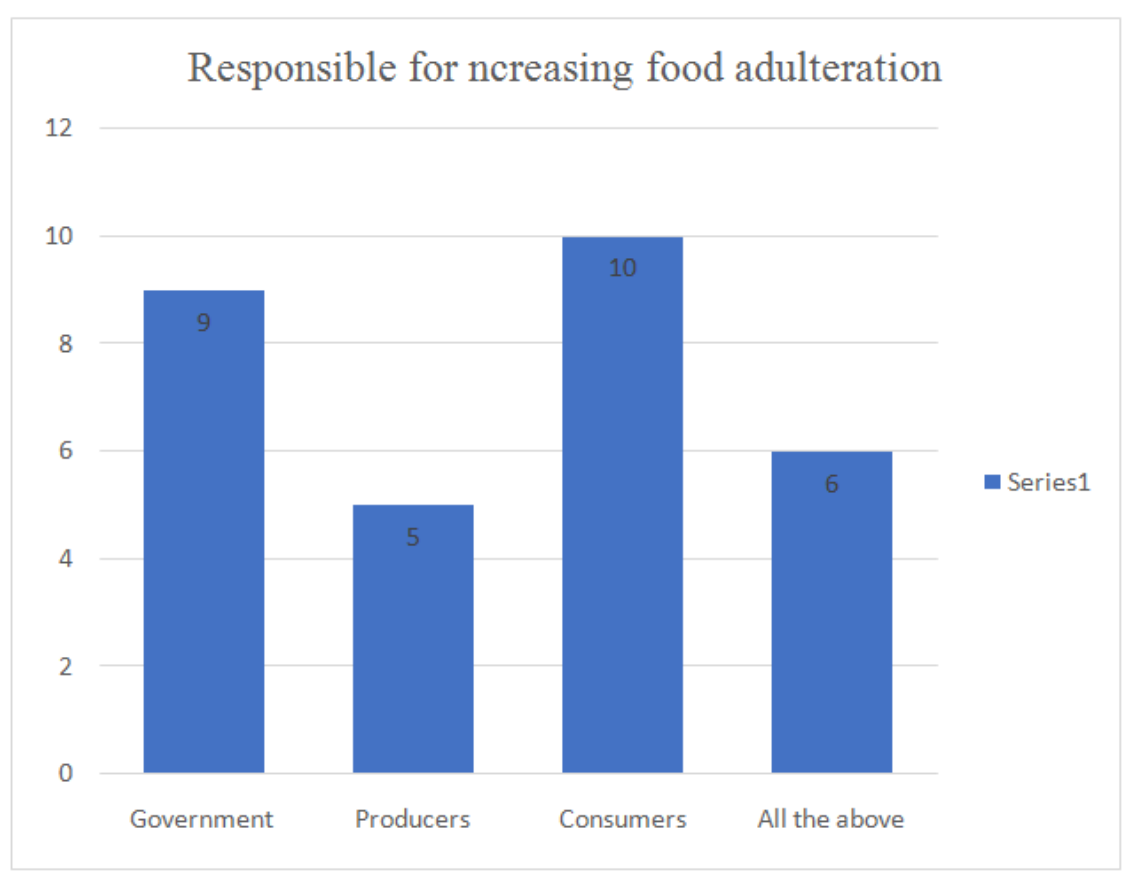

fig. 10

Their preference to the tinned and preserved food is an ample proof that our society is in peril. Majority of the consumers prefer fast food, soft drinks and fried items which are high calorie fat, sodium and low in fibre. These stuffs can cause heart diseases, diabetics and cancer. People are trapped by the ads in medias.

1.3 Harmful effects of food adulteration on consumers ${ }^{1}$ There are various health related issues arises due to the consumption of contaminated and adulterated food products. It is difficult for the consumers to identify the adulterated food items.The food can be adulterated naturally, intentionally or unintentionally. If any soil of oil in the sea would contaminate the marine livelihood and it would affect the fishes which turns to be poisonous. Similarly if any pesticides or fertilisers are spilled in the early stage of crops also leads to unintentional adulteration. The intentional are done by adding colour to the fruits to attract the people and stimulate them to buy those contaminated item. The below mentioned figure was published by the Chennai corporation about the harmful affects of food adulteration in various food items which are used in Chennai city.

fig.11

${ }^{1}$ http://www.chennaicorporation.gov.in/departments/health/adulteration.htm 
Few harmful effects are listed out below which shows how dangerous if the adulterated foods are consumed.

\begin{tabular}{|c|c|c|}
\hline FOOD ARTICLE & ADULTERANT & HARMFUL EFFECTS \\
\hline Bengal Gram dhal \& Thoor Dhal & Kesai dhal & lahyrism cancer \\
\hline Tea & Used tea leaves processed and coloured & Liver Disorder \\
\hline \multirow[t]{2}{*}{ Coffee Powder } & Tamarind seed, date seed powder & Diarrhoea \\
\hline & Chicory powder & Stomach disorder, Giddiness and joint pain \\
\hline Milk & Unhygenic water \& Starch & Stomach disorder \\
\hline Khoa & Starch \& Less Fat content & Less - nutritive value \\
\hline Wheat and other food grains (Bajra) & Ergot (a fungus containing poisonous substance) & Poisonous \\
\hline Sugar & Chalk powder & Stomach - Disorder \\
\hline Black powder & Papaya Seeds and light berrys & Stomach, liver problems \\
\hline Mustard powder & Argemone seeds & Epidemic dropsy \& Glucoma \\
\hline \multirow[t]{4}{*}{ Edible oils } & Argemone oil & Loss of eyesight, heart diseases, tumour \\
\hline & Mineral oil & Damage to liver,carcinogenic effects \\
\hline & Karanja oil & Heart problems, liver damage \\
\hline & Castor oil & Stomach problem \\
\hline Asafoetida & Foreign resins galbanum, colophony resin & dysentery \\
\hline \multirow[t]{3}{*}{ Turmeric powder } & Yellow aniline dyes & Carcinogenic \\
\hline & Non-permitted colourants like metanil yellow & Highly Carcinogenic \\
\hline & Tapioca starch & Stomach disorder \\
\hline \multirow[t]{2}{*}{ Chilli powder } & Brick powder, saw dust & Stomach problems \\
\hline & Artificial Colours & Cancer \\
\hline Sweets, Juices, Jam & Non-permitted coaltar dye, (Metanil Yellow) & Metanil yellow is toxic and carcinogenic \\
\hline Jaggery & Washing soda, chalkpowder & vomiting, diarrhoea \\
\hline Pulses (Green peas and dhal) & coaltar dye & stomach pain, ulcer \\
\hline Suapari & colour and saccharin & cancer \\
\hline
\end{tabular}

Adverse effects of adulteration on your health: There is no denial to the fact that adulteration is definitely not good. It poses a number of health hazards which include health diseases, weaken the immune system and lots more. Here are some more harmful effects that you might not be aware of.

- Leads to chronic health problems: There are many mineral oils which when added to the food items can result in paralysis, cancer etc. If pregnant women eat such food items it might lead to abortion or even damage the brain of the baby. Sometimes zinc substances result in vomiting or in severe cases it can result in diarrhea. Food colors that are added to the items can be the reason of liver damage, allergies and lots more. Thus you can say that adulteration can bring down your health and affect the quality of life.

- Increases the impurity in the food: As adulteration alters the composition of the food item, it

- increases the impurities thus making them imperfect for the consumption. If you consume such impure stuff you are bound to have side effects which can either be short-term or a long-term one.

- Lack of nutritional value: Ready-made food is made using poor quality ingredients which not only brings down the nutritional content but can have a change in taste as well if kept for a long time. So you compromise with the taste as well as your health. Thus you can say that adulteration is definitely not good. There can be a number of reasons of adulteration like the wrong packaging, use of insecticides or pesticides on the food, use of preservatives and lots more. One can do nothing about it but just take measures and try to use quality products only for cooking. This will ensure healthy cooking and you will be able to stay away from various kinds of health problems. So avoid ready-made food but healthy food prepared at home. ${ }^{2}$

\subsection{Existing few legal framework for abolishing food adulteration}

In India, there were a many pre-constitutional and post-constitutional legislations, rules and regulations that aims at food safety and health of the consumers on the basis of protection of consumers interest. They are complementary and supplementary each other in aiming and achieving food safety and quality measures . However due to diversity in the conditions /standards in different legislations and monitoring by different Departments and authorities, implementation problems raised and and there was a lack of importance given to safety standards over a period of time. The food producing firms faced lot of difficulties due to the various orders were given to govern different items which the country needed for consolidation. There are many legal frameworks for enhancing food safety. It legally establish a shield to safeguard the consumers by avoiding the consumption of adulterated food. The Government also tries to neglect the accessibility of the contaminated

${ }^{2}$ http://myessaypoint.com/harmful-effects-food-adulteration 
food products to reach the consumers but we have bothLaws and loopholes which the legislation made by the government makes ineffective and doesn't achieve its mission to eradicate adulterated foods completely from our society. In the year 1954, the Central Government consolidated legal provisions by way of comprehensive legislation (the Prevention of Food Adulteration Act 1954) to curb food adulteration and repealed all the laws in relation thereto in force on that date. The penalties for the offences in 1954 Act were set out and from time to time, considering the gravity of the issue, appropriate legislative amendments were made and the offences were categorised punishable with punishment extending upto life imprisonment. ${ }^{3}$

\section{$>$ Food Safety and Standards Act, 2006}

With the aim to consolidate all the previous existing laws, the Food Act was enacted by Parliament which establishes a single reference point for all matters relating to food safety and standards, by moving from multi- level, multi-departmental control to a single line of command.To this effect, the Food Act establishes an independent statutory Authority - the Food Safety and Standards Authority of India (Food Authority), which has been created for laying down science based standards for articles of food and to regulate their manufacture, storage, distribution, sale and import to ensure availability of safe and wholesome food for human consumption. The Food Act in chapter IX deals with offences and penalties which provides for punishments for contravention of the provisions of the Act. While section 48 describes how an offence may be committed in regard to food adulteration, sections 50 to 67 prescribes punishments in case an offence is committed. In particular, section 59 prescribes punishment for unsafe food. ${ }^{4}$

\section{$>$ Indian Penal Code, 1860}

The IPC in chapter XIV (Of Offences Affecting the Public Health, Safety, Convenience, Decency and Morals) prescribes punishment for adulteration of food or drink intended for sale (Section 272) and sale of noxious food or drink (Section 273).

1. Section 272 states that:

"Whoever adulterates any article of food or drink, so as to make such article noxious as food or drink, intending to sell such article as food or drink, or knowing it to be likely that the same will be sold as food or drink, shall be punished with imprisonment of either description for a term which may extend to six months, or with fine which may extend to one thousand rupees, or with both."

2. Section 273 states that:

"Whoever sells, or offers or exposes for sale, as food or drink, any article which has been rendered or has become noxious, or is in a state unfit for food or drink, knowing or having reason to believe that the same is noxious as food or drink, shall be punished with imprisonment of either description for a term which may extend to six months, or with fine which may extend to one thousand rupees, or with both."

\section{Suggestions}

$\checkmark \quad$ In our nation, for each state there must be a foundation for food safety which the state should sponsor with the advanced equipments which can be test the food safety.

$\checkmark$ Experts and specialised persons who are trained to check the food safety should visit eateries, food stores, the places were frequently foods are served like festival venue, and if any sort of adulteration or the contaminated foods are detected through scientific means.

$\checkmark \quad$ The police who are governed for food safety should have prior powers which are conferred on them under the sanction of legislation.

$\checkmark$ There should be certain provisions or specific Act which should provide judicial assistance in order to ensure people's health.

$\checkmark \quad$ The authority force which are operating under Ministry of health with the powers of seizure was a new idea which may require any changes like amendment to the Act called Food Safety Act. Guarding the procedure became a fundamental responsibility of the state.

$\checkmark$ There are many serious shortcomings in the Food Safety Bill, it must be rectified by suitable amendments and reformation of policy.

$\checkmark \quad$ Still many essential commodities and food items are raising in its price and the quality also differs and it clearly shows how it was adulterated, the government still lacking behind in order to take necessary actions.

$\checkmark \quad$ In order to eradicate starvation, all the essential commodities and food items prices to be regulated and it should be accessible to all classes. Even the people under Below Poverty Line (BPL) should get those essential items without any hurdles.

${ }^{3}$ http://www.livelaw.in/food-adulteration-laws-india-governments-response/

${ }^{4}$ Law Commission of India, Jan 2017

DOI: $10.9790 / 2402-1107016270$

Www.iosrjournals.org

68 | Page 


\section{Conclusion}

The demanding consumers and increasing number of food producers are the main reason to mislead the pattern of food safety. The imported food stuffs enables the producers to cheat the consumers. The consumers also ready to buy those products. To differentiate of those who take advantage of legal rules from the once who commit food adulteration is very difficult. The critical analysis of the consumers be me very strong enough to investigate and enquiry the specifications. In addition,ignorance and unfair market behaviours is endangering consumer health.So there is a need for sanctions and judicial penalties with adequate restraining force to halt this process. There exist only few informations about the food adulteration and contamination in our state.

More than urban zones, the highly affected zones are rural area. Therefore, proper awareness campaign and guarding aids to be provided to them by government to make alert for the accidental poisoning at village level. Attentive care also needed to prevent against the rising resistance in bacteria that causes dangerous diseases and morbidity. The institutions which are concerned especially in this field such as All India Institute of Hygiene \& Public Health and Indian Council of Medical Research must conduct various researches on the concept of human health and challenges faced when the contaminated products are intake and its impact and consequences. They also need to publish the related findings which would be helpful for the people to know about the actual fact. since we are having equal rights, we must fight for our legal right to get safe foods and hence the consumers should form association and fight for their rights. Significantly there are changes in the consumerism, food production and processing, marketing system and urbanisation which have rapid growth.

At present, it is important to take a serious note and its the needy to safe the agriculture, animal husbandry and measure to control the harvesting process before and after losses,. It also implies that more efficient food processing and distribution systems, and application of biotechnological techniques which can make foods not only readily available but free from adulteration and contamination. Hence, agriculture is not the backbone of our nation now it is important for our survival too. Only $16 \%$ of adulterated foods in Tamil Nadu as per the Newspaper report. But still many cases are unreported hence it should be completely eradicated, especially still there are many people who are not aware about the food-borne diseases.Basically, in Chennai it is transparent that people are influenced by artificial food items. It leads to various food-borne diseases and it may become as a health hazard.

\section{Reference}

Journal Paper:

[1] Gahukar, R.,T, Food adulteration and contamination in India: occurrence, implication and safety measures, International Journal of Basic science and applied science, vol.03,2014;

\section{E-Sources:}

[2] http://www.chennaicorporation.gov.in/departments/health/adulteration.htm

[3] http://myessaypoint.com/harmful-effects-food-adulteration

[4] http://www.livelaw.in/food-adulteration-laws-india-governments-response/

Reports:

[5] Law Commission of India, Jan 2017

\section{ANNEXE}

QUESTIONNAIRE ON FOOD ADULTERATION FOR CONSUMERS

What are the methods you choose to identify the adulterated food products?

a. Check the label of manufacturing dates and expiry dates

b. Check the authorisation

c. Buy only branded and government aided products

What is the main reason for food adulteration?

a. Cultural change

b. Agriculture methods were changed

c. High demand for perishable item

Why do you prefer to have street foods?

a. Attractiveness

b. Taste

c. Inexpensive

Are you interested in terrace farming?

a. Yes

b. No

If no, what are the factors restricting you to do so?

a. Insufficient of time

b. Waste of money

c. Lack of maintenance

Are you aware about the impact of adulterated food? 

a. Yes
b. No
If yes, What is your suggestion or control food adulteration?
a. Terrace gardening in home
b. Opting for traditional foods
c. Any other,

If any new eatable items are launched in the market, would you prefer to buy?
a. Yes
b. No

If yes, on what basis do you buy the product?

a. Price of the Product

b. Quality of the product

c. Promotional offer

d. Any Other

Who is responsible for increasing food adulteration products?
a. Government
b. Producers
c. Consumer
d. All the above

G.Vyralakshmi. "Food Adulteration and Contamination-A Catastrophe." IOSR Journal of Environmental Science, Toxicology and Food Technology (IOSR-JESTFT) 11.7 (2017): 62-70. 